\title{
Lymphoepithelial cyst of the upper esophagus
}

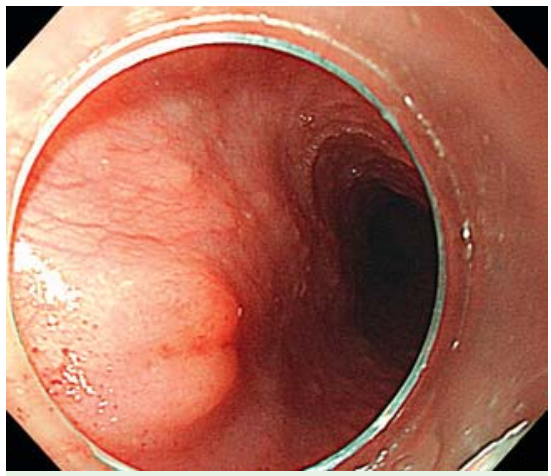

Fig. 1 Endoscopic view of the submucosal mass, $22 \mathrm{~cm}$ from the incisors below the upper esophageal sphincter.

A 61-year-old man underwent esophagogastroduodenoscopy as part of a general checkup at a private clinic, and was referred to our hospital with a suspected submucosal tumor of the esophagus. The patient had no symptoms and was in good health except that he was taking aspirin for angina pectoris, although he had not experienced any cardiac events in the past 6 years. On physical examination, the abdomen was flat and soft. Laboratory findings were within normal limits. The endoscopic examination showed a small submucosal tumor $22 \mathrm{~cm}$ from the incisors below the upper esophageal sphincter ( Fig. 1). Endoscopic ultrasonography showed a low echoic tumor, $5 \times 4 \mathrm{~mm}$ in size, in the submucosal layer of the esophagus ( $\bullet$ Fig. 2). The tumor was removed by endoscopic mucosal resection using a snare and sent for histological examination. The resected tumor was $9 \times 7 \times 4 \mathrm{~mm}$ in size. A unilocular cyst was found below the esophageal mucosa. The cyst was lined by stratified squamous epithelium surrounded by a florid lymphoid hyperplasia with germinal centers ( $\bullet$ Fig. 3). The histopathological examination confirmed the diagnosis of lymphoepithelial cyst. We plan to follow up the patient with gastroendoscopy in 1 year.

Lymphoepithelial cysts characteristically have a lining of stratified squamous epithelium and a complete or incomplete band of lymphoid tissue, resembling a lymph node. They are most often found in the lateral aspect of the neck or in the parotid gland [1] and are rarely found in other organs. Lymphoepithelial cysts of

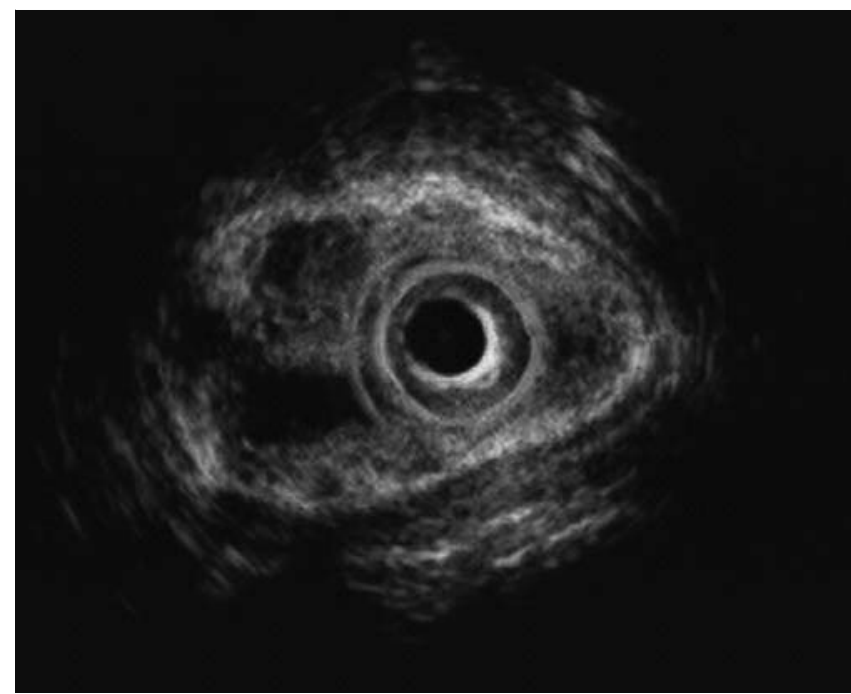

Fig. 2 Endoscopic ultrasonography showing a $5 \times 4 \mathrm{~mm}$, low echoic tumor in the submucosal layer of the esophagus.

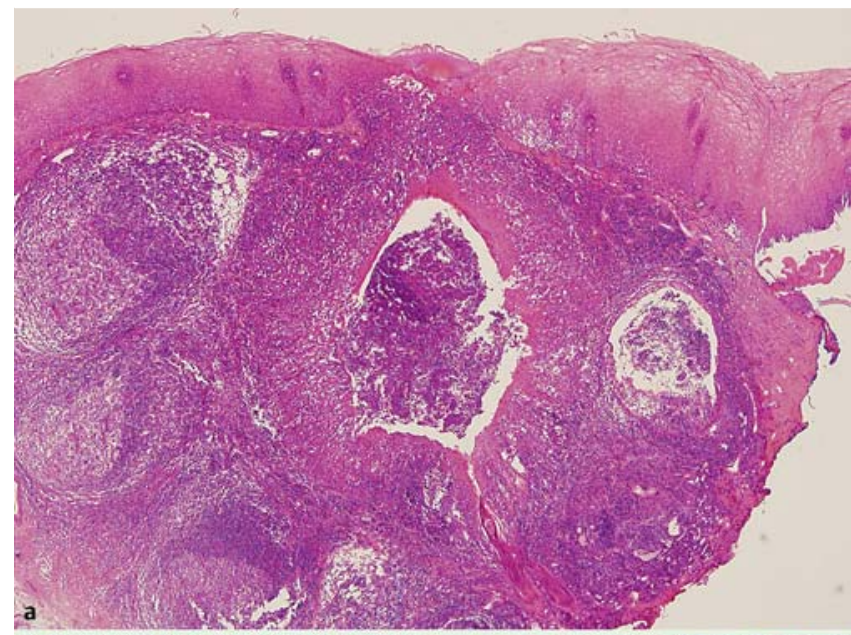

Fig. 3 a Lymphoepithelial cyst below the esophageal mucosa. (hematoxylin and eosin [H\&E], original magnification $\times 20$ ). b The cyst is lined by stratified squamous epithelium surrounded by a florid lymphoid hyperplasia with germinal centers (H\&E, original magnification $\times 40$ ).

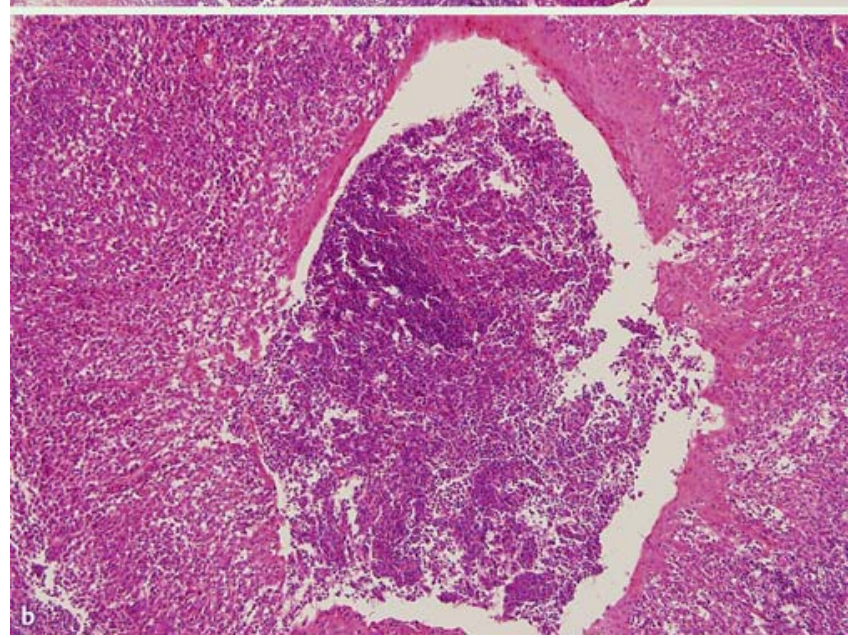

the esophagus are very rare. Since the first report of an esophageal lymphoepithelial cyst by Kataoka et al. in 1999 [2], two more cases have been reported $[3,4]$. All of them consisted of a submucosal tumor with a smooth lining, a homogeneous structure, and an echogenicity similar to the muscle layer on the endoscopic ultra- 
sonography; all these epithelial cysts were mature and benign. The histogenesis of lymphoepithelial cyst is unclear. It has been suggested that the lesions derive from remnants of the branchial cleft or originate in the squamous metaplasia of obstructed and dilated ducts [5]. Although it is difficult to explain the presence of a lymphoepithelial cyst in the esophagus based on these common hypotheses, a lymphoepithelial cyst may occur in the esophagus because the esophageal gland is similar to the parotid gland. Obstruction and cystic dilatation of an esophageal gland may lead to lymphocytic infiltration of the ductal epithelium [2].

In our case, the tumor was first suspected to be a cyst on the basis of endoscopic ultrasound and was successfully managed by endoscopic polypectomy. It is crucial that endoscopists consider lymphoepithelial cyst in the differential diagnosis of submucosal tumors of the esophagus.
Endoscopy_UCTN_Code_CCL_1AB_2AC_3AB

Competing interests: None

H. J. Noh ${ }^{1}$, J. S. Koo ${ }^{1}$, H. Y. Oh${ }^{1}$, J. W. Yun ${ }^{1}$, S. W. Jung ${ }^{1}$, E. S. Lee ${ }^{2}$, H. J. Yim ${ }^{1}$,

S. W. Lee ${ }^{1}$, J. H. Choi ${ }^{1}$

1 Division of Gastroenterology, Department of Internal Medicine, Korea University College of Medicine, Seoul, Korea

2 Department of Pathology, Korea University College of Medicine, Seoul, Korea

\section{References}

1 Marie B, Labouyrie E, Scheid $P$ et al. Human immunodeficiency virus type 1 in an unusual cystic lymphoepithelial lesion of the lung. Histopathology 1997; 31: 83-86

2 Shinichi K, Takaaki C, Takashi H. Esophageal lyrnphoepithelial. Cyst Dig Endoscopy 1999; 11: $332-336$

3 Sinya A, Yoshio N, Yamatsuji $T$ et al. Lymphoepithelial cyst of the cervical esophagus. J Gastroenterol 2006; 41: 88-90
4 Lee KB, Lim HC, Park HY et al. A case of lymphoepithelial cyst in the lower esophagus. Korean J Gastrointest Endosc 2009; 39: $352-354$

5 Jeffrey W, Glosser D, Carlos A et al. Branchial cleft or cervical lymphoepithelial cysts. J Am Dent Assoc 2003; 134: 81 - 86

Bibliography

DOI $10.1055 / \mathrm{s}-0030-1256514$

Endoscopy 2011; 43: E254-E255

(c) Georg Thieme Verlag KG Stuttgart · New York . ISSN 0013-726X

\section{Corresponding author}

\section{J.S. Koo}

Division of Gastroenterology

Department of Internal Medicine

Korea University Ansan Hospital

516 Gojandong Danwongu

Ansan 425-707

Korea

Fax: +82-31-412-5582

jskoo@korea.ac.kr 